\title{
Prognostic Value of Tumor Stem Cells and Anaplastic Lymphoma Kinase Expression in Patients with Primary Cutaneous Melanoma
}

\author{
Titov Konstantin Sergeevich ${ }^{1}$, Kazakov Alexey Mikhailovich ${ }^{2, *}$, Baryshnikova Maria Anatolievna ${ }^{2}$, \\ Zaryanov Dmitry Albertovich ${ }^{1}$, Ryabchikov Denis Anatolyevich ${ }^{2}$ \\ ${ }^{1}$ Department of Surgical Treatment of Tumors of the Skin and Soft Tissues, Medical Faculty, Moscow Clinical Scientific Center Named After \\ A. S. Loginova, Moscow, Russia. \\ ${ }^{2}$ Chemotherapy Department No. 1, Faculty of Clinical Oncology N. N. Trapeznikov, Federal State Budgetary Institution «N. N. Blokhin \\ National Medical Research Center of Oncology» of the Ministry of Health of the Russian Federation, Moscow, Russia
}

\author{
Email address: \\ Ks-titov@mail.ru (T. K. Sergeevich), Hordavii@yandex.ru (K. A. Mikhailovich), ma_ba@mail.ru (B. M. Anatolievna), \\ Dmitry..zaryanov@yandex.ru (Z. D. Albertovich) dr.denisr@mail.ru (R. D. Anatolyevich) \\ ${ }^{*}$ Corresponding author
}

\section{To cite this article:}

Titov Konstantin Sergeevich, Kazakov Alexey Mikhailovich, Baryshnikova Maria Anatolievna, Zaryanov Dmitry Albertovich, Ryabchikov Denis Anatolyevich. Prognostic Value of Tumor Stem Cells and Anaplastic Lymphoma Kinase Expression in Patients with Primary Cutaneous Melanoma. Journal of Cancer Treatment and Research. Vol. 7, No. 3, 2019, pp. 62-68. doi: 10.11648/j.jctr.20190703.13

Received: September 16, 2019; Accepted: October 7, 2019; Published: October 20, 2019

\begin{abstract}
Melanoma is the most aggressive cutaneous neoplasm. Cancer stem cells (CSCs) may be one of the reasons for the low sensitivity of melanoma to chemotherapy, the short curative effect and the development of resistance to the targeted therapy, as well as the lack of efficiency of immune checkpoint inhibitors and disease relapses. The aim of our the study was to determine the influence of the expression of stem cells markers (ABCB5 и CD133) and tyrosine kinases of mutated Anaplastic Lymphoma Kinase (ALK) genes found in primary tumors on survival of patients with stage I-II cutaneous melanomas. Materials of 48 patients with melanoma were used, and their morphological parameters (tumor thickness, invasion level, lymphoid infiltration) were assessed. The expression of CSCs markers, mutant kinases was determined using the immunohistochemical method. The statistical significance of the influence of the parameters studied on the overall (OS) and 2year relapse-free (RFS) survival was assessed by calculating the correlation coefficient using the rank method. Stem cell markers were found in $25(52 \%)$ of 48 patients with cutaneous melanomas. ABCB5 was expressed in 20 (54\%), CD133 was expressed in 17 (46\%) patients. The co-expression of both markers was observed in 12 patients (32\%). The 2-year OS in the group with CSC markers expressed (first group) was $76 \%$, whereas in the group w/o such markers expressed (second group), the OS was $91.31 \%$. The rates of RFS also differed between the two groups: in the first, RFS was $80 \%$, and in the second one, it reached $91.31 \%$. CD133 marker was found in $80 \%$ of the first group patients with metastases and relapses. A strong correlation was found between the increase percentage of cells expressing $\mathrm{CD} 133$ and the increase invasion level. $(\mathrm{P}=0.879$ $\pm 0.107)$. A strong correlation was found between the increase percentage of cells expressing ABCB5 and the increase tumor thickness. ( $\mathrm{P}=0.943 \pm 0.088)$. The expression of mutant ALK was found in $28 \%$ of patients with CSC markers detected, and no statistically significant correlation between the prognosis and the presence of ALK was found. ABCB5 and CD133+ are promising markers of tumor stem cells applicable to predicting the clinical course of primary cutaneous melanomas. A correlation between $\mathrm{ABCB} 5$ and $\mathrm{CD} 133$ markers and a number of morphological parameters shows the importance of their study for understanding the fundamental mechanisms of melanoma carcinogenesis. The inhibition of ABCB5 and CD133+ markers and mutant ALK may serve as a target for the therapy for melanoma in perspective.
\end{abstract}

Keywords: Tumor Stem Cell, ABCB5, CD133, ALK, Lymphoid Infiltration, 2-Year Survival 


\section{Introduction}

A cutaneous melanoma is an aggressive tumor consisting of melanocytes, which constitutes $3-4 \%$ of all malignant skin neoplasms in humans, but at the same time it may account for up to $80 \%$ of deaths in this group of patients [1].

Modern curative approaches to melanomas include surgeries, targeted therapy, immunotherapy, chemotherapy and radiotherapy. The efficiency of drug treatment is reduced due to the development of various mechanisms of drug resistance [2]. One of these mechanisms is the presence of so-called cancer stem cells (CSCs), which constitute about $0.5-5 \%$ of the mass of malignant neoplasms and exhibit a number of properties that drastically differentiate them from other melanoma cells. CSCs are one of the reasons for the low sensitivity of melanomas to chemotherapy, the short curative effect of the targeted therapy, the lack of efficiency of immunotherapy, and the rapid progression together with high frequency of metastasis and recurrence [3]. Cases of long-term recurrence (in 5-10 years or more) are at the moment associated with the CSC metastasis. CSCs make it possible to activate alternative signaling pathways of growth and survival, such as WNT5A, PI3K, EGFR signaling pathways. MAPKs don't play the role of the main promoter pathway in this process, thereby providing resistance to kinase inhibitors of this cascade, such as MEK, RAS and BRAF [4, 5]. One possible mechanism of alternative activation of tumor growth and progression is the increased expression of the mutated Anaplastic Lymphoma Kinase ALK gene kinase. ALK is a receptor tyrosine kinase with an increased ability to autoactivate, which causes uncontrolled cell division. [6] We detected the ALK expression in patients with primary cutaneous melanoma [7], however, the correlation between the expression of CSC markers and mutant kinases is of interest for study.

At the moment, the most characteristic CSC phenotype of melanomas is represented by the following markers: ABCB5, CD133, CD20, CD271, which also determine many properties of CSCs [8]. ABCB5 is a plasma membrane protein. It is also a member of the human P-glycoprotein family (ABC transporter). This marker is associated with progression, resistance to chemotherapy and targeted therapy, and faster metastasis [9]. Provided the melanoma cell line knockout by ABCB5 gene, the tumor mass volume decreased by more than 3 times compared with the melanoma control cell line during 9 months of growth [10].

$\mathrm{ABCB} 5$ is also associated with multiresistance to many chemotherapeutic drugs (dacarbazine, cisplatin, paclitaxel etc.). The experiment conducted with ABCB5 inhibitors (monoclonal antibodies and RNA interference) showed a firm decrease in resistance to these drugs $[10,11]$. One of the most important functions of $\mathrm{ABCB} 5$ is the provocation of transition of CSCs to the so-called slow-cycling period. In this condition, the autoreduplication period of tumor cells subpopulations exceeds 4 weeks [12]. The transition to the slow-cycling period makes tumor stem cells almost immune to both chemotherapy and targeted therapy, thus giving another explanation to the phenomenon of short curative effect of the drug therapy, in addition to its role in the process of activation of alternative signaling pathways [13, 14]. The ability to transition to the slow-cycling period partly explains the phenomenon of distant recurrence and activation of metastatic foci in 5-10 years or more after the treatment of the primary tumor. [15]. This effect is achieved through the cytokine cascade IL-1 $\beta$-IL8-CXCR1. [16]. Another important marker of melanoma CSCs is CD133, which is a transmembrane protein associated with tumor stem cells, fast-growing tumors and metastatic tumors, including melanoma [17]. The properties of this marker are associated with the increased metastatic activity, as its hyper-expression increases the expression of matrix metalloproteinases (MMPs-2) destroying the intercellular matrix and contributing to further invasion, growth and metastasis [18]. One of the most important properties of CD133 is the ability of melanoma cells, which express this marker, to participate in vasculogenic mimicry (alternative angiogenesis), increasing tumor invasion and metastasis. It is worth noting that the cells involved in tumor vasculogenic mimicry also show increased expression of ABCB5. [19, 20]

Thus, such $\mathrm{CSCs}$ as $\mathrm{CD} 133+$ and $\mathrm{ABCB} 5+$ may potentially be the cause of many unsolved problems associated with the treatment of cutaneous melanomas. In addition to the above-mentioned information, one of their main properties is the formation of new colonies of tumor cells resistant to previous therapy, which have more aggressive phenotypes, as clones of dead cells are replaced by new ones that are more adapted to specific conditions. All of the previously mentioned facts make CSCs extremely important in predicting, and later in choosing the optimal tactics of treatment by targeted drugs aimed at CSCs in patients with the markers of such cells [21].

\section{Materials and Methods}

The study was conducted on the surgical material taken from 48 patients diagnosed with stage I-II cutaneous melanomas. All patients underwent surgical treatment limited to tumor excision, and then patients with IIB and IIC stages additionally received adjuvant immunotherapy with interferon- $a-2 b$ (up to a maximum of 12 months). The median age of the patients was 58 years. 4 patients with IA stage $(8.3 \%), 24$ patients with IB stage $(50 \%), 8$ patients with IIA stage $(16.6 \%), 4$ patients with IIB stage $(8.3 \%), 8$ patients with IIC stage (16.6\%) participated in the study. In $30(62.5 \%)$ cases, a superficial spreading melanoma of pigment skin cells was detected, and in 18 (37.5\%) cases, a nodular melanoma of pigment skin cells was detected.

The study was conducted with the help of paraffin blocks containing the surgical material taken from 48 patients with primary cutaneous melanoma that underwent surgical treatment at the Moscow Clinical Research and Practice Center named after A. S. Loginov of the Moscow Healthcare Department in 2016.

We fixed the material to be used in the routine histological 
study with $10 \%$ neutral buffered formalin for 24 hours, then poured it into paraffin, prepared sections of 4-5 micron thickness, and stained them with Hematoxylin and Eosin. During the morphological analysis, the following features were assessed: type of melanoma, tumor (Breslow) thickness, invasion (Clark) level, ulceration, degree of lymphocytic immune infiltration, and mitotic index (MI).

For immunohistochemical study of the expression of ABCB5 and CD133 markers, the sections of paraffin blocks were dewaxed and rehydrated in xylol and ethanol using the standard method. Antigens were unmasked during the process of treatment of the sections in a citrate buffer on a water bath at $95^{\circ} \mathrm{C}$ (Dako, Denmark) for 30 minutes. To block the endogenous peroxidase activity, the sections were subject to dark incubation with $3 \%$ hydrogen peroxide for 5 minutes. To block the non-specific binding activity of antibodies, the sections were incubated with a $10 \%$ solution of bovine serum albumin for 15 minutes. To detect antigens, monoclonal antibodies were used: CD133 (rabbit polyclonal to human $\mathrm{CD} 133$, dilution ratio 1:100, ab19898, Abcam) and ABCB5 (a clone of 5H3C6, dilution ratio 1:200, ab140667, Abcam). The incubation with antibodies was conducted at $4{ }^{\circ} \mathrm{C}$ for $16-18$ hours.

The incubation with secondary antibodies labeled with peroxidase (REAL Envision+ kit, Dako) was conducted at room temperature for 20 minutes. The chromogen Diaminobenzidine (Invitrogen) was used to visualize the immunohistochemical reaction. The sections were additionally stained with Mayer's Hematoxylin (Sigma-
Aldrich) and enclosed in Shandon Synthetic Mountant (Therrmo). The results of the study were assessed using a light microscope NIKON 80i (Germany). The expression was assessed based on the intensity scale $(0,1+, 2+, 3+)$ and the percent $(0-100 \%)$ of positive cells detected among all tumor cells in the sample.

The analysis of the expression of the ALK tyrosine kinase was carried out on sections made from the same blocks using the immunohistochemical method. The IHC study conducted with monoclonal antibodies D57.3 to ALK was carried out using the Ventana immunostainer. The Ventana system was used as a detection system for ALK.

The statistical significance of the results of the study was assessed by calculating the correlation coefficient using the rank method (Spearman's method).

\section{Results}

After analyzing the data obtained, which is given in Tables 1 and 2, a correlation between the presence of the melanoma CSC markers and a number of morphological parameters, as well as between the presence of CSCs and the ALK was detected.

Table 1 summarizes the data on the determination of CSC markers, as well as the data on morphological parameters of tumors and some characteristics of patients included in this study. Table 2 summarizes the results of the ALK determination in patients with the melanoma CSCs markers.

Table 1. Current condition, presence of CSC markers and morphological parameters.

\begin{tabular}{|c|c|c|c|c|c|c|c|c|}
\hline $\begin{array}{l}\text { Condition of patients at } \\
\text { the time of the study }\end{array}$ & No. & $\begin{array}{l}\text { ABCB5 } \\
\text { Intensity } \\
\text { score (\% of } \\
\text { stained cells) }\end{array}$ & $\begin{array}{l}\text { CD133 } \\
\text { Intensity score } \\
\text { (\% of stained } \\
\text { cells) }\end{array}$ & $\begin{array}{l}\text { Clark's } \\
\text { level }\end{array}$ & $\begin{array}{l}\text { Breslow's } \\
\text { thickness } \\
(\mathbf{m m})\end{array}$ & $\begin{array}{l}\text { Mitotic } \\
\text { index }\end{array}$ & $\begin{array}{l}\text { Lymphoid } \\
\text { infiltration } \\
(0-\text { no; } 1 \text { - low; } 2 \text { - } \\
\text { moderate; } 3 \text { - large })\end{array}$ & $\begin{array}{l}\text { Ulceration } \\
(0-\text { no; } 1- \\
\text { yes })\end{array}$ \\
\hline Died of disease progression & No. 1 & $2(60)$ & 0 & 3 & 10 & $>1$ per sq. $\mathrm{mm}$ & 3 & 1 \\
\hline Died of disease progression & No. 2 & $1(80)$ & 0 & 1 & 1 & $>1$ per sq. $\mathrm{mm}$ & 3 & 1 \\
\hline Died of disease progression & No. 3 & $3(80)$ & $3(30)$ & 3 & 0.6 & $<1$ per sq. $\mathrm{mm}$ & 2 & 1 \\
\hline Died of disease progression & No. 4 & $3(80)$ & $3(40)$ & 4 & 5 & $>1$ per sq. $\mathrm{mm}$ & 2 & 1 \\
\hline Died of disease progression & No. 5 & $2(90)$ & $3(10)$ & 2 & 2 & $>1$ per sq. $\mathrm{mm}$ & 1 & 0 \\
\hline Died of disease progression & No. 6 & $2(95)$ & 0 & 5 & 6 & $>1$ per sq. $\mathrm{mm}$ & 3 & 1 \\
\hline Alive. Disease progresses. & No. 7 & 0 & $3(50)$ & 3 & 4 & $>1$ per sq. $\mathrm{mm}$ & 3 & 1 \\
\hline Alive. Disease progresses. & No. 8 & $3(90)$ & $3(20)$ & 3 & 2 & $<1$ per sq. mm & 3 & 1 \\
\hline Alive. Disease progresses. & No. 9 & $1(80)$ & $1(5)$ & 3 & 0.5 & $>1$ per sq. $\mathrm{mm}$ & 3 & 1 \\
\hline Alive. Disease progresses. & No. 10 & $1(80)$ & $2(50)$ & 3 & 0.3 & $>1$ per sq. $\mathrm{mm}$ & 2 & 1 \\
\hline Alive. Disease progresses. & No. 11 & $2(80)$ & 0 & 4 & 3 & $<1$ per sq. mm & 3 & 1 \\
\hline Alive. Remission & No. 13 & 0 & $2(80)$ & 3 & 0.6 & $>1$ per sq. $\mathrm{mm}$ & 3 & 0 \\
\hline Alive. Remission & No. 14 & $3(20)$ & $2(10)$ & 4 & 5 & $>1$ per sq. $\mathrm{mm}$ & 0 & 1 \\
\hline Alive. Remission & No. 15 & $3(50)$ & $2(15)$ & 2 & 0.4 & $>1$ per sq. $\mathrm{mm}$ & 3 & 1 \\
\hline Alive. Remission & No. 16 & $2(90)$ & 0 & 3 & 1.1 & $<1$ per sq. mm & 2 & 0 \\
\hline Alive. Remission & No. 17 & 0 & $2(30)$ & 3 & 2 & $>1$ per sq. $\mathrm{mm}$ & 3 & 1 \\
\hline Alive. Remission & No. 18 & $3(90)$ & $3(20)$ & 2 & 1.5 & $>1$ per sq. $\mathrm{mm}$ & 2 & 0 \\
\hline Alive. Remission & No. 19 & $3(90)$ & 0 & 3 & 1.5 & $<1$ per sq. mm & 3 & 0 \\
\hline Alive. Remission & No. 20 & $3(80)$ & $2(20)$ & 2 & 1 & $<1$ per sq. $\mathrm{mm}$ & 2 & 0 \\
\hline Alive. Remission & No. 21 & $2(90)$ & 0 & 2 & 0.5 & $<1$ per sq. $\mathrm{mm}$ & 2 & 0 \\
\hline Alive. Remission & No. 22 & $2(90)$ & 0 & 4 & 0.6 & $>1$ per sq. $\mathrm{mm}$ & 2 & 1 \\
\hline Alive. Remission & No. 23 & 0 & $2(40)$ & 2 & 1 & $>1$ per sq. $\mathrm{mm}$ & 3 & 1 \\
\hline Alive. Remission & No. 24 & $3(90)$ & $2(20)$ & 2 & 2 & $>1$ per sq. $\mathrm{mm}$ & 2 & 0 \\
\hline Alive. Remission & No. 25 & 0 & $2(30)$ & 3 & 2 & $<1$ per sq. $\mathrm{mm}$ & 0 & 0 \\
\hline
\end{tabular}


Table 2. ALK expression in patients with the CSC markers of a primary cutaneous melanoma.

\begin{tabular}{llll}
\hline Condition of patients at the time of the study & ALK & ABCB5 Intensity score (\% of stained cells) & CD133 Intensity score (\% of stained cells) \\
\hline Alive. Remission & - & $3(95)$ & $3(95)$ \\
Died of disease progression & - & $2(60)$ & 0 \\
Died of disease progression & + & $1(80)$ & 0 \\
Alive. Remission & - & 0 & $2(80)$ \\
Alive. Disease progresses. & + & 0 & $3(50)$ \\
Alive. Remission & + & $3(20)$ & $2(10)$ \\
Alive. Remission & - & $3(50)$ & $2(15)$ \\
Alive. Disease progresses. & - & $3(90)$ & $3(20)$ \\
Alive. Remission & + & $2(90)$ & 0 \\
Alive. Remission & - & 0 & $2(30)$ \\
Alive. Remission & - & $3(90)$ & $3(20)$ \\
Alive. Disease progresses. & - & $1(80)$ & $1(5)$ \\
Died of disease progression & - & $3(80)$ & $3(30)$ \\
Died of disease progression & + & $3(80)$ & $3(40)$ \\
Died of disease progression & - & $2(90)$ & $3(10)$ \\
Alive. Remission & - & $3(90)$ & 0 \\
Alive. Remission & + & $3(80)$ & $2(20)$ \\
Alive. Remission & - & $2(90)$ & 0 \\
Died of disease progression & + & $2(95)$ & 0 \\
Alive. Remission & - & $2(90)$ & 0 \\
Alive. Disease progresses. & - & $1(80)$ & $2(50)$ \\
Alive. Disease progresses. & - & $2(80)$ & 0 \\
Alive. Remission & - & 0 & $2(40)$ \\
Alive. Remission & - & $3(90)$ & $2(20)$ \\
Alive. Remission & - & 0 & $2(30)$ \\
\hline
\end{tabular}

Stem cell markers were detected in $25(52 \%)$ of 48 patients. ABCB5 was detected in $20(54 \%)$ patients with primary cutaneous melanoma, and CD133 was detected in 17 $(46 \%)$ of them. Co-expression was observed in 12 patients
(32\%). ALK was found in $28 \%$ of patients with detected CSC markers. Figures 1, 2 and 3 show the results of the IHC staining of tumor material and ABCB5, CD133, ALK positive cells.

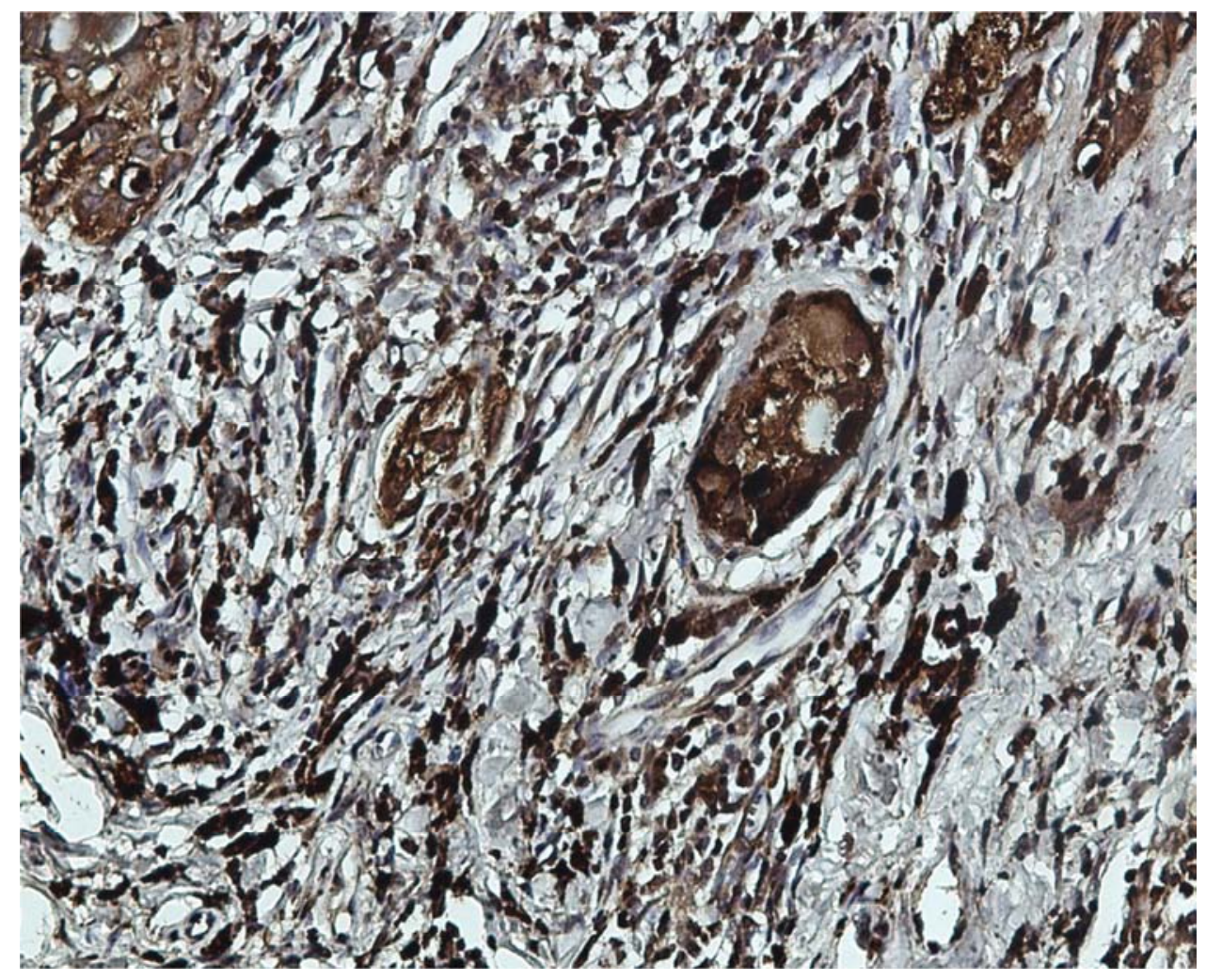

Figure 1. ABCB5 marker expression by stem cells (intensity 3+). 


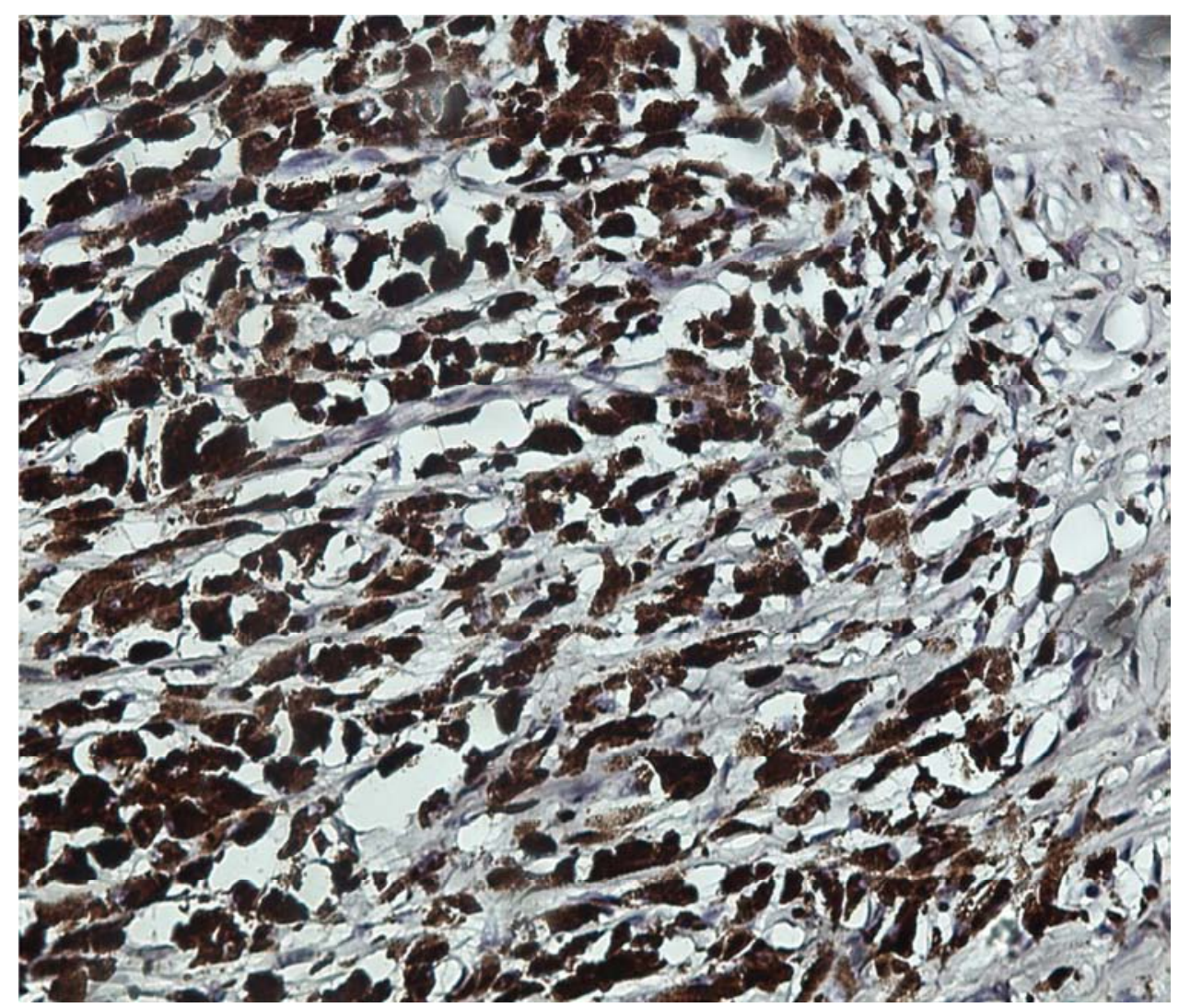

Figure 2. CD133 marker expression by stem cells (intensity 3+).

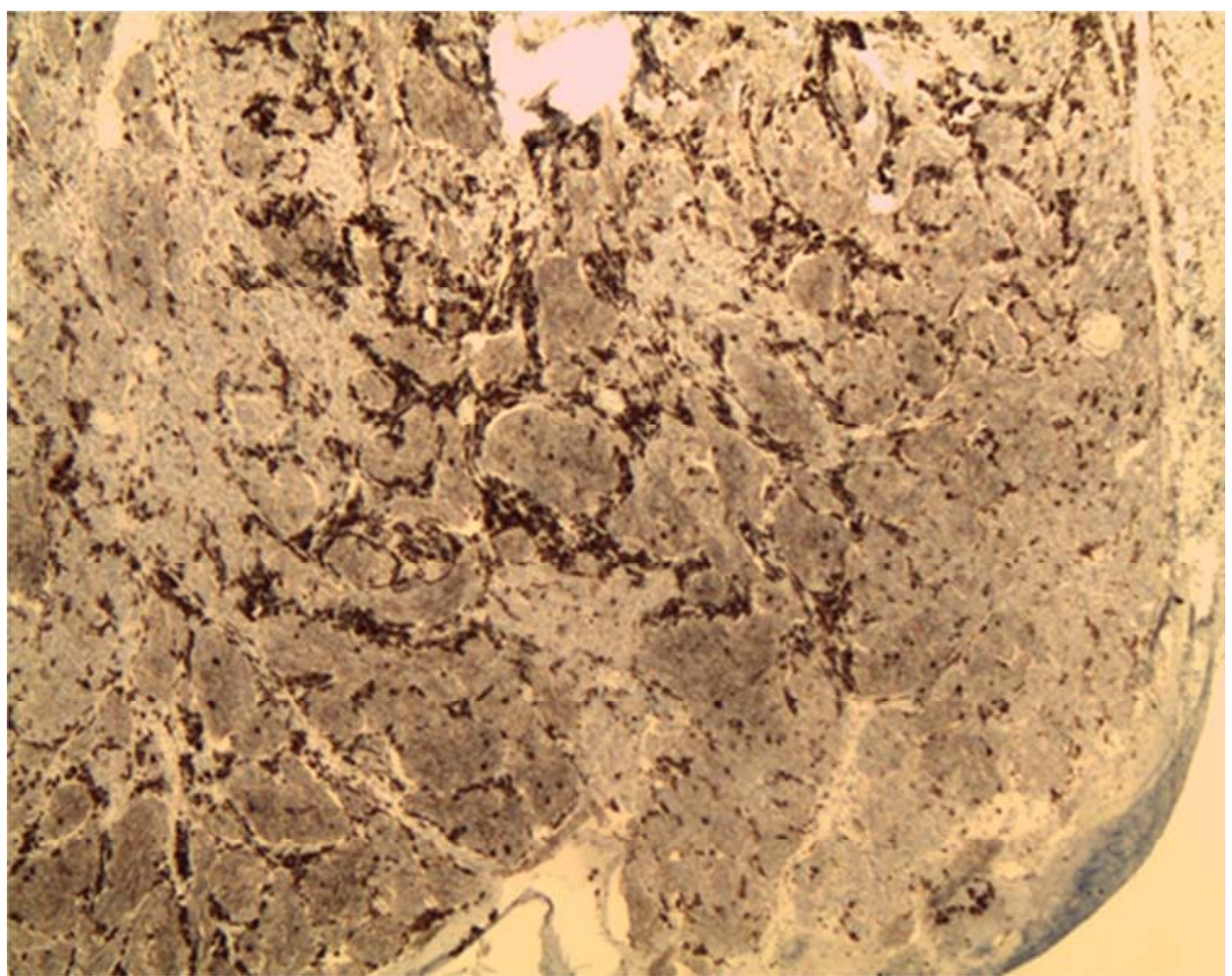

Figure 3. ALK expression (staining intensity 3+).

The patients were divided into groups according to the presence or absence of expression of CSC markers: the first group included 25 people with ABCB5 and/or CD133 expression, and the second group included 23 patients with no CSC expression. The comparison between the first and the second group of patients revealed the following: the 2-year 
overall survival (OS) in the first group was $76 \%$, whereas it reached $91.31 \%$ in the second group. The rates of relapsefree survival (RFS) also differed between the two groups: in the first group, RFS was $80 \%$, and in the second one, it reached $91.31 \%$.

As you can see from the summary table, different ratios of CSC markers cannot serve as a predictor of 2-year survival at the very least. Such result may be connected with insufficient study period, as the prognostic potential of these markers may appear in the analysis of 5 and 10-year survival.

The presence of CD133 in $80 \%$ of the first group patients with metastases and relapses makes us consider the prognostic value. This phenomenon may be associated with an increased level of CD133-positive cell invasion in such patients and, as a consequence, with a high probability of metastasis, which is confirmed by the reference data from all over the world given above.

We detected a strong correlation between an increase in the percentage of cells expressing CD133 and an increase in the Clark's level of invasion ( $\mathrm{P}=0.879 \pm 0.107)$.

We also detected a strong correlation between an increase in the percentage of cells expressing $\mathrm{ABCB} 5$ and an increase in the Breslow's thickness $(\mathrm{P}=0.943 \pm 0.088)$, which also proves the fact of participation of ABCB5 in tumor progression.

An increase in the degree of lymphoid infiltration was found in patients with an increased percentage of cells expressing $\mathrm{ABCB} 5$, which may indicate the presence of mechanisms that increase the immunogenicity of CSCs carrying this marker. $(\mathrm{P}=0.8130 \pm 0.137)$

ALK was found in $28 \%$ of patients with CSC markers, indicating the possibility of activation of this proliferation mechanism in such patients. Perhaps, the activation of this pathway is one of the factors contributing to the formation of melanoma CSCs, or its consequence. This signaling pathway is detected in $4-8 \%$ of people with primary cutaneous melanoma, and it is possible to activate it simultaneously with other driver mutations, such as BRAF. Such dual blockade of these mutations can play an important role in prolonging the progression-free survival in this group of patients. Mutant kinases were more often associated with the presence of $\mathrm{ABCB} 5+$ of the tumor, which may indicate a correlation between the two events. This phenomenon requires further study. There was no statistically significant correlation between the 2-year prognosis and the presence of mutant kinases.

\section{Discussion}

There is a large number of works devoted to the determination of CSCs for various tumors, including primary skin melanoma. As mentioned above, a fairly large number of markers associated with CSCs of melanoma were found. Most attention is currently focused on CD 133 and ABCB5. The results of various studies relating to their role in the pathogenesis of melanoma, and even their relationship directly to CSCs are controversial. For example, a metaanalysis of 299 melanoma cases dedicated to the expression of CD133 by skin melanoma cells showed that only the presence of $\mathrm{CD} 133$ does not always indicate that the cell belongs to $\mathrm{CSC}$, but a combination with $\mathrm{ABCB} 5$ expression gives a more accurate result. [22] As for the association of CSC with an increased degree of invasion and growth rate, in this case our results are absolutely consistent with other studies. [23] The relationship of the markers of CSC with metastasis and a long-term prognosis is also interesting, in the study published by Klein WM et all, it was shown that in the analysis of 84 cases of metastatic melanoma, in each case, expression of markers of CSC was found in metastasis, which again positively correlates with our results. [24]

As for ALK expression, what is currently a promising direction is the study of the use of ALK inhibitors in ALK positive melanoma resistant to BRAF inhibitors [25]. Our results can help identify groups of patients who may potentially need an ALK expression test, as our data suggest a positive relationship between ALK and CSC, which may play a role in acquiring resistance to target therapy.

\section{Conclusion}

Thus, the determination of tumor stem cell markers (ABCB5 and CD133) expression is a potentially promising direction in predicting the clinical course of primary cutaneous melanoma. These molecules may become targets for a new kind of targeted melanoma therapy in the future. The detection of a severe lymphoid infiltration accompanied with ABCB5 expression as shown by us, opens up new possibilities in understanding the pathogenesis of such tumor, which are yet to be investigated.

The presence of the expression of tyrosine kinase of ALK mutated gene in primary cutaneous melanoma opens up a promising possibility of using ALK inhibitors (Ceritinib, Crizotinib, TAE-684 etc.) in this subgroup of patients.

\section{References}

[1] Valko-Rokytovska M, Bruchata K, Simkova J, etc. Current trends in the treatment of malignant melanoma. Neoplasma. 2016; 63 (3): 333-41. doi: 10.4149/301_151015N533.

[2] Beatriz Domingues, José Manuel Lopes, Paula Soares, etc. Melanoma treatment in review. Published online 2018 Jun 7. doi: 10.2147/ITT.S134842.

[3] Nicholas Nguyen, Kasey L Couts, Yuchun Luo, etc. Understanding melanoma stem cells. Melanoma Manag. 2015 May; 2 (2): 179-188. Published online 2015 May 18. doi: $10.2217 / \mathrm{mmt} .15 .4$.

[4] Hartman ML, Czyz M. MITF in melanoma: mechanisms behind its expression and activity. Cell Mol Life Sci 2015; 72: 1249-60. doi: 10.1007/s00018-014-1791-0.

[5] Chatterjee A, Stockwell PA, Ahn A, etc. Genome-wide methylation sequencing of paired primary and metastatic cell lines identifies common DNA methylation changes and a role for EBF3 as a candidate epigenetic driver of melanoma metastasis. Oncotarget 2016; 8: 6085-101. doi: 10.18632/oncotarget.14042. 
[6] Busam KJ, Villain RE, Lum T, et al.: Primary and Metastatic Cutaneous Melanomas Express ALK Through Alternative Transcriptional Initiation. Am J Surg Pathol. 2016; 40 (6): 786-95. DOI: 10.1097/PAS.0000000000000611.

[7] K. S. Titov, D. L. Rotin, A. M. Kazakov etc. The Frequency of Expression of Tyrosine Kinase of ALK Gene and TAG-72 Oncoprotein in Primary Cutaneous Melanoma. Russian Journal of Biotherapy. 2018. 3. 50-54. DOI: 10.17650/17269784-2018-17-3-50-54.

[8] Giorgio Parmiani. Melanoma Cancer Stem Cells: Markers and Functions. Cancers (Basel). 2016 Mar; 8 (3): 34. Published online 2016 Mar 11. doi: 10.3390/cancers8030034.

[9] Setia N, Abbas O, Sousa Y, Garb JL, Mahalingam M. Profiling of $\mathrm{ABC}$ transporters $\mathrm{ABCB} 5, \mathrm{ABCF} 2$ and nestinpositive stem cells in nevi, in situ and invasive melanoma. Mod Pathol. 2012; 25: 1169-75. DOI: 10.1038/modpathol.2012.71.

[10] Brian J. Wilson, Karim R. Saab, Jie Ma, etc. ABCB5 maintains melanoma-initiating cells through a proinflammatory cytokine signaling circuit. Cancer Res. 2014 Aug 1; 74 (15): 4196-4207. Published online 2014 Jun 16. doi: 10.1158/0008-5472.CAN-14-0582.

[11] Frank NY, Margaryan A, Huang Y, Schatton T, etc. ABCB5mediated doxorubicin transport and chemoresistance in human malignant melanoma. Cancer Res. 2005 May 15; 65 (10): 4320-33. DOI: 10.1158/0008-5472.CAN-04-3327.

[12] Roesch A, Fukunaga-Kalabis M, Schmidt EC, etc. A temporarily distinct subpopulation of slow-cycling melanoma cells is required for continuous tumor growth. Cell. 2010 May 14; 141 (4): 583-94. doi: 10.1016/j.cell.2010.04.020.

[13] Murphy GF, Wilson BJ, Girouard SD, Frank NY, Frank MH Stem cells and targeted approaches to melanoma cure. Mol Aspects Med. 2013 doi: 10.1016/j.mam.2013.10.003. Epub 2013 Oct 19.

[14] Antonio Ahn, Aniruddha Chatterjee and Michael R. Eccles. The Slow Cycling Phenotype: A Growing Problem for Treatment Resistance in Melanoma. Molecular cancer Therapeutics. Published June 2017 DOI: 10.1158/15357163.MCT-16-0535.

[15] M Perego, M Maurer, J X Wang, etc. A slow-cycling subpopulation of melanoma cells with highly invasive properties. Oncogene volume 37, pages 302-312 (18 January 2018). DOI: https://doi.org/10.1038/onc.2017.341
[16] Luo Y, Ellis LZ, Dallaglio K, et al. Side Population Cells from Human Melanoma Tumors Reveal Diverse Mechanisms for Chemoresistance. The Journal of investigative dermatology. 2012. doi: 10.1038/jid.2012.161. Epub 2012 May 24.

[17] Zhong Li. CD133: a stem cell biomarker and beyond. Exp Hematol Oncol. 2013; 2: 17. Published online 2013 Jul 1. doi: $10.1186 / 2162-3619-2-17$.

[18] Zhang M, Liu Y, Feng H, Bian X, Zhao W, Yang Z, Gu B, Li Z. CD133 Affects the Invasive Ability of HCT116 Cells by Regulating TIMP-2. Am J Pathol. 2013; 182 (2): 565-576. doi: 10.1016/j.ajpath.2012.10.015.

[19] Chiou-Yan Lai, Brian E. Schwartz, and Mei-Yu Hsu. CD133+ Melanoma Subpopulations Contribute to Perivascular Niche Morphogenesis and Tumorigenicity through Vasculogenic Mimicry. Cancer Res. 2012 Oct 1; 72 (19): 5111-5118. Published online 2012 Aug 3. doi: 10.1158/0008-5472.CAN12-0624.

[20] Yashwant m. deo, Tibor keler. Bispecific molecules directed to tumor associated glycoprotein-72 and fc receptor. 1997.

[21] Alamodi AA, Eshaq AM, Hassan SY, etc. Cancer stem cell as therapeutic target for melanoma treatment. Histol Histopathol. 2016 Dec; 31 (12): 1291-301. doi: 10.14670/HH-11-791.

[22] Zahra Madjd, MD, PhD, Elham Erfani, Elmira Gheytanchi, et all. Expression of CD133 Cancer Stem Cell Marker in Melanoma: A Systematic Review and Meta-Analysis doi: https://doi.org/10.5301/jbm.5000209.

[23] Lai CY, Schwartz BE, Hsu MY. CD133+ melanoma subpopulations contribute to perivascular niche morphogenesis and tumorigenicity through vasculogenic mimicry. Cancer Res. 2012 Oct 1; 72 (19): 5111-8. doi: 10.1158/0008-5472.CAN-12-0624. Epub 2012 Aug 3.

[24] Klein WM, Wu BP, Zhao S, et all. Increased expression of stem cell markers in malignant melanoma. Mod Pathol. 2007 Jan; 20 (1): 102-7. Epub 2006 Nov 24. DOI: 10.1038/modpathol.3800720.

[25] Radoslav Janostiak, Parmanand Malvi, and Narendra Wajapeyee. Anaplastic Lymphoma Kinase Confers Resistance to BRAF Kinase Inhibitors in Melanoma. iScience. 2019 Jun 28; 16: 453-467. Published online 2019 Jun 8. doi: 10.1016/j.isci.2019.06.001. 